\title{
Ebola re-emerges in Sierra Leone
}

Case announced hours after World Health Organization declares spread of virus stopped in West Africa.

\section{Richard Van Noorden}

15 January 2016

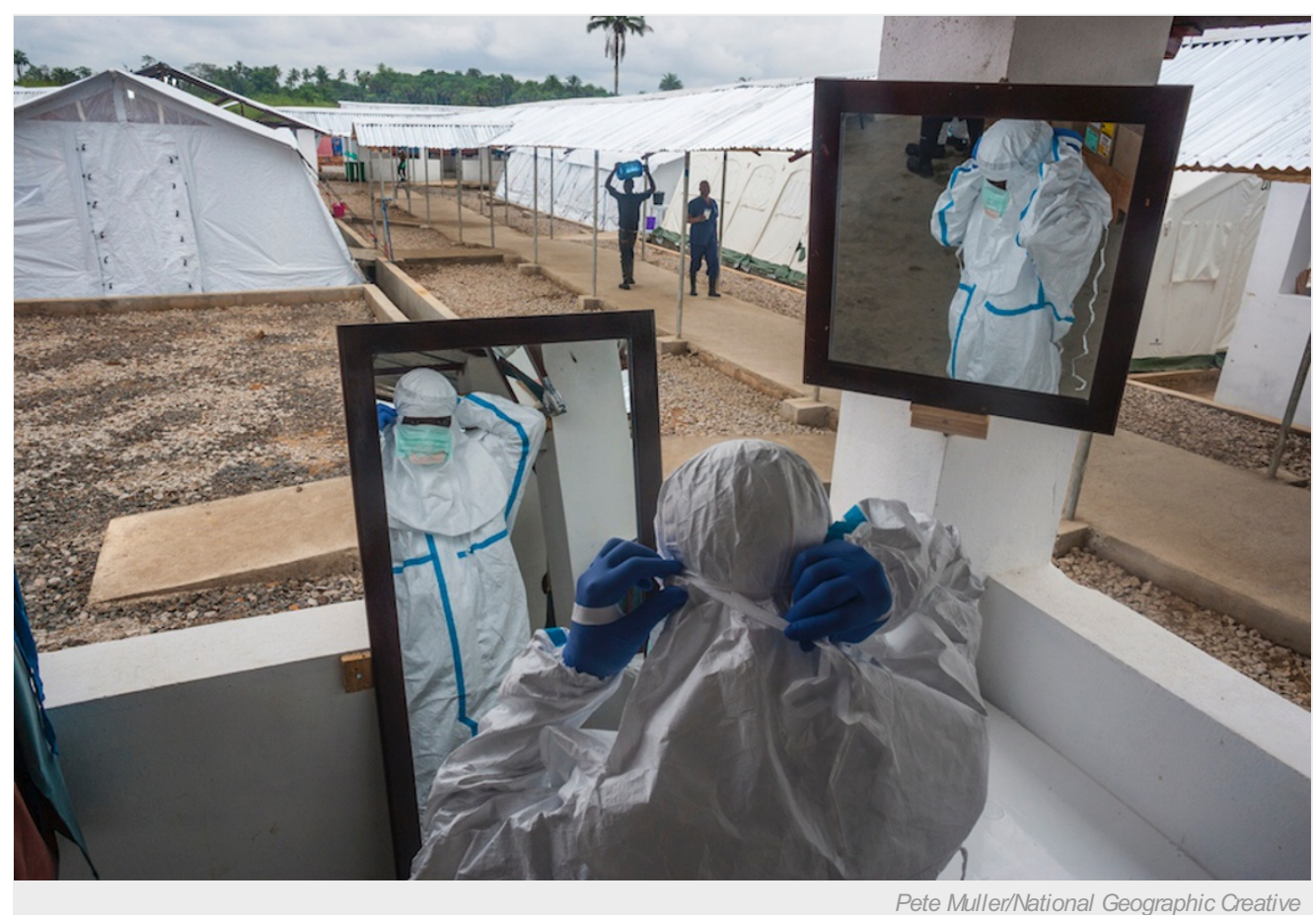

A treatment facility in the Lunsar Ebola Treatment Centre in Port Loko, Sierra Leone.

When the World Health Organization (WHO) declared on 14 January that the spread of Ebola had been halted in West Africa, it cautioned that cases of the virus might yet re-emerge. That is exactly what has happened in Sierra Leone, where another death from Ebola was announced hours after the WHO's statement.

Health officials told reporters that a 22-year-old woman had died in Magburaka after falling ill in Baomoi Luma, near the border of Guinea. A test for Ebola was confirmed positive only after her death, which occurred earlier in the week, raising concerns that she may have been in contact with others while contagious.

The case is Sierra Leone's first since it was declared free of Ebola on 7 November 2015, although the country was still in a 90-day period of enhanced surveillance. The WHO and local partners say that they are investigating its origin and identifying the woman's contacts.

\section{Flare-ups expected}

Although the epidemic phase of Ebola seems to be over, isolated cases were expected. The WHO considers human transmission of the virus to have halted when a country has gone 42 days (twice the virus's incubation period) with no new cases — but the virus can persist in survivors for months in semen, as well as in tissues such as the eye, the central nervous system, the prostate gland and the placenta. It also remains hidden in animal reservoirs.

Liberia, for example, was pronounced Ebola-free in May 2015, but the virus flared up twice before the WHO could declare the country clear of the virus again on 14 January. "We are now at a critical period in the Ebola epidemic as we move from managing cases and patients to managing the residual risk of new infections," Bruce Aylward, special representative for the WHO's Ebola response, noted in the organization's press-released statement at the time. 
sexual transmission of the disease was confirmed in Liberia last October, Armand Sprecher, a public-health specialist with Médecins Sans Frontières (also known as Doctors without Borders) in Brussels, wrote in an editorial: "The challenge with sexual transmission is not that it would be a source of many new Ebola virus disease cases, but that it may be a source of late cases."

Nature | doi:10.1038/nature.2016.19180 